\title{
Evaluating Monetary Policy When Nominal Interest Rates are Almost Zero
}

\author{
Ippei Fujiwara*† \\ Research and Statistics Department, Bank of Japan \\ 2-1-1 Nihonbashi-Hongokucho, Chuo-ku, Tokyo 103-8660, JAPAN
}

March 2004

\begin{abstract}
The non-negativity constraint on nominal interest rates may have been a major factor behind a putative structural break in the effectiveness of monetary policy. To check for the existence of such a break without making prior assumptions about timing, and to enable comparison between pre- and post-break monetary policy, we employ an identified Markov switching VAR framework. Estimation results support the existence of a structural break around the time when the de-facto zero nominal interest rate policy was resumed and the effectiveness of monetary policy is seen to weaken since then although slightly positive effects from monetary easing still exist.
\end{abstract}

JEL Classification: C33; E50.

Key words: Markov Switching VAR; Monetary Policy; Zero Nominal Interest Rate Floor.

\footnotetext{
${ }^{*}$ Email.: ippei.fujiwara@boj.or.jp.

$\dagger$ The author would like to thank Michael Ehrmann (ECB) both for his valuable comments and for sharing the code used to derive impulse responses from the Markov switching VAR model and Hans-Martin Krolzig (Humbolt University) for leading me to the field of Markov Switching models. Helpful comments were also received from Kosuke Aoki (Universitat Pompeu Fabra), Kanemi Ban (Osaka University), Shigeru Fujita (University of California, San Diego), Munehisa Kasuya (Bank of Japan), Ryuzo Miyao (Kobe University), Yutaka Soejima (Bank of Japan), Toshitaka Sekine (Bank of Japan) and seminar participants at Osaka University and the Bank of Japan. Importantly, the views expressed in this paper should not be taken to be those of the Bank of Japan nor of any of its respective monetary policy or other decision making bodies. Any errors remain solely the responsibility of the author.
} 


\section{Introduction}

It is often argued that the effectiveness of monetary policy has significantly weakened during the 1990s. When we look closely at the Japanese macroeconomy during the "lost decade" since 1990, ${ }^{1}$ monetary policy does not indeed seem to have had any obviously stimulatory effects on the economy. Miyao (2000) points out three reasons for this: "(i) the yen's appreciation to just over 80 yen per dollar, (ii) the Bank of Japan's actions to lower the official discount rate or the call rate to a record low below $1 \%$, and (iii) the series of bank failures that disclosed the serious bad loan problem in Japan's financial sector." Moreover, as concluded in Kimura, Kobayashi, Muranaga and Ugai (2002), the introduction of the zero nominal interest rate may be expected to have lessened the effectiveness of monetary policy still further, by reducing the scope for easing interest rates or, to put it another way, by denying the economy the traditional interest rate channel for monetary policy transmission.

The principal aim of this paper is to check whether, due to the introduction of the zero nominal interest rate, the effects of monetary policy on the real economy are characterized by a structural break. Given such a break, the further aim is then to improve our understanding of the currently prevailing relationship between monetary instruments and other economic variables, especially when nominal interest rates are almost zero.

In order to check for the existence of such a break without making prior assumptions about timing, and to enable comparison between pre- and post-break monetary policy, a recently pioneered econometric technique known as identified Markov Switching Vector Autoregression (MSVAR) is employed in this paper.

\footnotetext{
${ }^{1}$ Hayashi and Prescott (2002) name the 1990s in Japan the "lost decade", and search for the causes of the economic stagnation that characterizes the period.

Researchers have recently begun to pay more attention to Japan's unusual experiences since the collapse of the bubble economy: cf. Bayoumi and Collyns (2000) and Ramaswamy and Rendu (2000).
} 
With this method, structural breaks are expressed in terms of Markovian regime shifts, where the latter are themselves one of the outputs of the estimation process. As long as the regimes identified by the Markov switching estimation are long-lived and distinct, it is appropriate to analyse the characteristics of a putative structural break by comparing the impulse responses of different regimes.

The paper is laid out as follows. Section two reviews the related literature: looking first at recent work on Markov switching regressions, and then turning to previous research that makes use of VARs to investigate monetary policy transmission mechanism. Section three provides the framework for analyses in this paper. The estimation process for the Markov switching model, the derivation of the impulse responses, and the use of bootstrapping to establish confidence intervals are explained. In section four, results from an MSVAR model with an explicit interest rate channel are demonstrated. Section five further constructs two MSVAR models with an implicit interest rate channel, which suit the current monetary policy scheme employed by the Bank of Japan, and results from these models are also summarized. The aim here is to enable us to attain insight into the effectiveness of the Bank of Japan's current "quantitative easing" policy. Section six concludes the paper.

\section{Previous Research}

This section reviews previous research, first of all on Markov switching models, and then on VAR models of the monetary policy transmission mechanism.

\subsection{Markov Switching Models}

Hamilton (1989) first introduces Markov switching models in time series econometrics. Hamilton's research is based on the stylized fact not only that there exists nonlinearity in economic time series, but that this nonlinearity is espe- 
cially pronounced in the asymmetric business cycle, which Neftci (1984) and others find, for the US, to be characterized by the combination of long but gradual expansions and short but sudden recessions. By recognizing this periodic shift from a positive growth rate to a negative growth rate as a recurrent feature of the US business cycle, Hamilton (1989) presents a method for dating expansions and recessions that offers an alternative to the conventional NBER method.

Since this seminal research, Markov switching models have been widely applied in the analysis of various economic phenomena, including, among others, Phillips curves with regime shifts and the co-movement of the European business cycle. The various applications of Markov switching models and how to estimate these models in detail are shown in Krolzig (1997), and Kim and Nelson (1999).

Krolzig (1998) develops MSVAR, ${ }^{2}$ a user-friendly application of MSVAR which runs on $\mathbf{O x}$. This software enables easy access to the Markov switching technology, the programming for which is normally very complicated. The econometric analysis below makes use of MSVAR.

The possibility that impulse response functions could be derived within an MSVAR framework was first recognized by Krolzig and Toro (1999). They derive impulse response functions which can account for endogenous regime shifts. However, since my research interest lies in comparing the impulse responses of different regimes, it is necessary to compute "regime-dependent impulse responses", in other words separate impulse response functions for each regime. A recent paper [Ehrmann, Ellison and Valla (2003)] shows how to derive regime dependent impulse response functions. The analysis below follows their methodology.

\footnotetext{
${ }^{2}$ MSVAR is downloadable at www.econ.ox.ac.uk/people/members/krolzighm.htm.
} 


\subsection{Analysis of Monetary Policy Using VARs}

There is a vast amount of research on the monetary policy transmission mechanism using VARs. Indeed the monetary transmission provides the subject matter for Sims' seminal paper on identified VAR [Sims (1980)], which is wellknown for its critique of traditional large macro models for their implausible identifications (the "Sims critique"). Since Sims' paper, a considerable amount of research, making use of various identification schemes has been published. This literature is required to engage with the problem of identification of the VAR innovations, and this usually involves making assumptions about the contemporaneous relationships among the macro variables within the system. In this context, some authors, such as Christiano, Eichenbaum and Evans (1999), use the Choleski decomposition, which allows identification by assuming that the system is recursive, while others such as Leeper, Sims and Zha (1996) employ a non-recursive framework ${ }^{3}$ for identifying monetary policy shocks.

As for the research on the Japanese monetary policy transmission mechanism, Teruyama (2001) offers a good summary of developments in this field. In considering whether or not there has been a structural change in the monetary transmission mechanism, Miyao (2000) estimates both three variable and four variable VARs (the variables in the former are industrial production, the call rate and the monetary base, while the latter also includes the nominal exchange rate), in which all non-financial variables are expressed as log differences. He concludes that according to the testing procedure suggested by Christiano (1986) and Cecchetti and Karras (1994), the effectiveness of monetary policy has significantly weakened during the 1990s. Similarly, looking at impulse responses to monetary expansion under the zero nominal interest rate, Kimura, Kobayashi, Muranaga and Ugai (2002) estimate a time-varying VAR and con-

\footnotetext{
${ }^{3}$ The non-recursive framework for identification is pioneered by Bernanke (1986) and Sims (1986).
} 
clude that the inflation rate is now less responsive than before to an expansion in the monetary base.

Although the aim of the current paper is similar to that of Miyao (2000, 2002), structural breaks are expressed as Markovian regime shifts, and the model is estimated in levels. ${ }^{4}$ Both Sims (1980) and other related papers recommend against differencing even if the variables are not stationary. ${ }^{5}$ As the main purpose of a VAR study is not to determine parameter estimates but to identify inter-relationships among variables, differencing should not be employed because it throws away important information about co-movements in the data. The impulse responses obtained here may therefore be rich in information.

\section{$3 \quad$ Methodology}

In this analysis, all the parameters including intercepts, coefficients and variance covariance matrices for the reduced-form VAR are assumed to switch according to a hidden Markov chain. ${ }^{6}$ Denoting the number of regimes by $m$ and the number of lags $p$ respectively, the equation to be estimated is expressed as follows.

$$
Y_{t}=v\left(s_{t}\right)+B_{1}\left(s_{t}\right) Y_{t-1}+\cdots+B_{p}\left(s_{t}\right) Y_{t-p}+A\left(s_{t}\right) U_{t}
$$

$$
s_{t}=1, \cdots, m
$$

\footnotetext{
${ }^{4}$ It should be mentioned, however, that there is no substantial change in the results when differenced data are employed, since the smoothed regime probabilities are quite similar whether the estimation is carried out using levels or differences. A possible explanation for this, as pointed out in Miyao (1996), is the lack of evidence to support the M2 velocity cointegration relationship after 1985 .

${ }^{5}$ Non-stationarity of the data is less problematic in the estimation here since the residuals behave quite reasonably. Further, Sims, Stock and Watson (1990) claim that even if the system includes non-stationary variables, the estimator would still be consistent in an estimation in levels.

${ }^{6}$ According to Krolzig's (1997) notation, this specification may be referred as: MSIAH $(m)$ $\operatorname{VAR}(p)$.
} 


$$
U_{t} \sim N\left(0, I_{K}\right)
$$

$K$ is the dimension of the coefficient matrix $B_{p}$, i.e. it describes the number of endogenous variables. $U_{t}$, the vector of fundamental disturbances, is assumed to be uncorrelated at all leads and lags. When the number of regimes $m$ is two ${ }^{7}$, equation (1) is reduced to

$$
Y_{t}=\left\{\begin{array}{l}
v_{1}+B_{1}^{1} Y_{t-1}+\cdots+B_{p}^{1} Y_{t-p}+A^{1} U_{t}, \text { if } s_{t}=1 \\
v_{2}+B_{1}^{2} Y_{t-1}+\cdots+B_{p}^{2} Y_{t-1}+A^{2} U_{t}, \text { if } s_{t}=2
\end{array},\right.
$$

where $s_{t}$ is assumed to follow the discrete time and discrete state stochastic process of a hidden Markov chain. The probability of regime $i$ occurring next period given that the current regime is $j^{8}$ is fixed. This stochastic process is defined by the transition matrix $P$ as follows.

$$
\begin{gathered}
P=\left(\begin{array}{ll}
p_{11} & p_{12} \\
p_{21} & p_{22}
\end{array}\right) \\
p_{i, j}=\operatorname{Pr}\left(s_{t+1}=j \mid s_{t}=i\right), \sum_{j=1}^{2} p_{i j}=1 \forall i, j \in(1,2)
\end{gathered}
$$

Since this is a regime switching model, the number of regimes needs to be fixed beforehand. It is true that the likelihood ratio test embedded in MSVAR may be used to determine the optimal number of regimes. However, Krolzig (1997) claims that due to the existence of nuisance parameters, the likelihood ratio test against the null hypothesis of linearity or a greater number of regimes has no asymptotic standard distribution. ${ }^{9}$ Furthermore, it is desirable for each

\footnotetext{
${ }^{7}$ Superscripts denote the regime.

${ }^{8} i$ may be equal to $j . i$ and $j$ are either 1 or 2 in this case.

${ }^{9}$ One of the regularity conditions for the likelihood ratio test to have an asymptotic Chi square distribution is that the information matrix is non-singular. However, this condition fails to hold if an $m$ state model is to be fitted when the true process has $m-1$ states because the parameters which describe $m$ th state are unidentified under the null hypothesis.
} 
regime to be sufficiently long-lasting, as opposed to frequently changing, to allow for investigation of the existence of structural breaks. ${ }^{10}$ Therefore, the model should be kept as parsimonious as possible. Taking these observations into account, the number of regimes is fixed at two.

\subsection{Estimation}

Estimation of the Markov switching model is conducted by applying the EM (Expectation-Maximization) algorithm. ${ }^{11}$ As mentioned in Ehrmann, Ellison and Valla (2003), "since the Markov chain is hidden, the likelihood function has a recursive nature: optimal inference in the current period depends on the optimal inference made in the previous period. Under such conditions the likelihood cannot be maximized using standard techniques." Under the procedure for applying the EM algorithm, first, the hidden Markov chain is inferred in the expectation step for a given set of parameters, then the parameters for the hidden Markov chain are re-estimated in the maximization step. These two steps are repeated until convergence is achieved.

This procedure estimates the coefficient matrix, the variance-covariance matrix for each regime, the transition matrix, and the optimal inference for the regimes throughout the sample period. The latter are referred to as the regime probabilities $\widehat{\xi}_{t}^{i}$ defined below, where $T$ denotes the end period for the estimation.

$$
\widehat{\xi}_{t}^{i}=\operatorname{Pr}\left(s_{t}=i\right) \text { for } i=1,2 \text { and } t=1, \cdots T
$$

\footnotetext{
${ }^{10}$ Indeed, Ehrmann, Ellison and Valla (2003) claim "Regime-dependent impulse response functions are conditional on a given regime prevailing at the time of the disturbance and throughout the duration of the response. The validity of regime conditioning depends on the time horizon of the impulse response and the expected duration of the regime. As long as the time horizon is not excessive and the transition matrix predicts regimes which are highly persistent then the conditioning is valid and regime-dependent impulse response functions are a useful analytical tool. For a longer time horizon or frequently switching regimes, it would be more attractive to condition on the expected path of the regime throughout the response."

${ }^{11}$ For details of the estimation, see Hamilton (1994) and Krolzig (1997).
} 
There exist three types of regime probabilities, the choice among which depends on differences in the available information. The following analysis uses smoothed probabilities which are defined as below.

$$
\widehat{\xi}_{t \mid \tau}^{i}, t<\tau \leq T
$$

In this paper, MSVARs are estimated from January 1985 to December 2003. The number of lags is chosen by appeal to the Schwarz Bayesian information criterion (SBIC) ${ }^{12}$, in spite of the fact claimed by Garcia (1998) that Markov switching models raise problems with testing hypotheses when there is a nuisance parameter that is not identified under the null hypothesis.

\subsection{Identification}

It is popular to identify the system for contemporaneous relationships between macroeconomic variables. To this end, some authors, such as Christiano, Eichenbaum and Evans (1999), make use of the Choleski decomposition, which assumes that the system is recursive and hence allows identification. This identification scheme is also employed in this paper.

Matrix $A^{i}$ is computed from the regime dependent variance covariance matrix from the reduced form VAR, $\Sigma^{i}$.

$$
\Sigma^{i}=E\left(A^{i} U_{t} U_{t}^{\prime} A^{i \prime}\right)=A^{i} I A^{i \prime}=A^{i} A^{i \prime}
$$

Matrix $A^{i}$ has $K^{2}$ elements, on the other hand $\Sigma^{i}$ has only $\frac{K(K+1)}{2}$ elements. In order for $A^{i}$ to be defined from equation (5), there must exist $\frac{K(K-1)}{2}$ missing restrictions. Sims (1980) introduces additional restrictions based on the recursive structure so that $A^{i}$ is just identified from equation (5). If $A^{i}$ is restricted

\footnotetext{
${ }^{12}$ Further, as more parameters such as the transition matrix need to be estimated in the Markov switching model, the optimal number of lags tends to be smaller than in the linear model.
} 
to be a lower triangular matrix, $A^{i}$ is easily recovered by applying the Choleski decomposition to equation (5).

\subsection{Impulse Responses}

Regime-dependent impulse response functions depict the relationship between endogenous variables and fundamental disturbances within a regime. As is standard for impulse responses, these illustrate expected changes in the endogenous variables after a one standard deviation shock to one of the fundamental disturbances. However, regime-dependent impulse response functions are conditional on the regime prevailing at the time of the disturbance continuing to prevail throughout the duration of the responses. Therefore, as mentioned earlier, this concept is valid only when each regime is persistent.

Mathematically, the regime-dependent impulse response function at time $t+h$ when a one standard error shock to the $k$ th fundamental disturbance occurs at time $t$ and the prevailing regime is $i$, is expressed as follows.

$$
\left.\frac{\partial E_{t} Y_{t+h}}{\partial U_{k, t}}\right|_{s_{t}=\cdots=s_{t+h}=i}=\theta_{k, h}^{i}, \text { for } h \geq 0
$$

A series of $K$ dimensional response vectors $\theta_{k, 1}^{i}, \ldots, \theta_{k, h}^{i}$ show the responses of the endogenous variables to a shock to the $k$ th fundamental disturbance. Here, the duration for the impulse response is set at 48 months as this is reasonable time span relative to the expected duration of each regime estimated below.

These response vectors are computed by combining unrestricted parameter estimates of the reduced-form Markov switching vector autoregression model $B$ and the identified matrix $A$. The first response vector is easily computed since this is the case where a standard unitary shock is added to the $k$ th fundamental disturbance as captured by the initial disturbance vector $U_{0}=(0, \cdots, 1, \cdots, 0)$, which is a vector of zeros apart from the $k$ th element which is one. Using 
equation (2), this may be written

$$
\widehat{\theta}_{k, 0}^{i}=\widehat{A}^{i} U_{0}
$$

The remaining response vectors are also easily calculated by solving forward for the endogenous variables in equation (2).

$$
\widehat{\theta}_{k, h}^{i}=\sum_{j=1}^{\min (h, p)}\left(\widehat{B}_{j}^{i}\right)^{h-j-1} \widehat{A}^{i} U_{0}, \text { for } h>0
$$

\subsection{Confidence Intervals}

Bootstrapping is now widely used to gauge the precision of the impulse response function. ${ }^{13}$ However, the bootstrapping in Markov switching models is complicated due to the existence of the hidden Markov chain determining the regimes. Therefore, it is first of all necessary to compute an artificial history for the regimes. We follow the procedure advocated by Ehrmann, Ellison and Valla (2003) and described below.

\section{1) Create a history for the hidden regimes $s_{t}$}

This can be done recursively using the definition of a Markov process in equations (3) and (4), and replacing the transition matrix with its estimated value $\widehat{P}$. At each time $t$ we draw a random number from a uniform [0,1] distribution and compare it with the conditional transition probabilities to determine whether there is a switch in regime.

\section{2) Create a history for the endogenous variables}

\footnotetext{
${ }^{13}$ It is widely recognized that the bootstrapping method may be inconsistent for autoregressive models with unit roots. However, the case is not so clear for non-stationary VARs. Although Choi (2002) reports that bootstrapping may be inconsistent for non-stationary bivariate AR processes, this point is not considered explicitly here since there are as yet no firm conclusions for VARs with more than two variables.
} 
Again, this is done recursively, on the basis of equation (2). All parameters are replaced by their estimated values and new fundamental residuals are drawn from the normal distribution $U_{t} \sim N\left(0, I_{K}\right)$. Equation (2) can then be applied recursively using the artificial regime history created in step one.

\section{3) Estimate an MSVAR}

Using the data from the artificial history created in step two, a MSVAR is re-estimated. Estimation gives bootstrapped estimates of the parameters $\left\{\widetilde{v}^{i}, \widetilde{B}_{1}^{i}, \cdots, \widetilde{B}_{p}^{i}, \widetilde{\Sigma}^{i}\right\}$ for $i=1,2$, the transition matrix $\widetilde{P}$, and the smoothed probabilities $\widehat{\xi}_{t}^{i}$ for $i=1,2$ and $t=1, \ldots, T$.

\section{4) Impose identifying restrictions}

Applying the same restrictions as the data, a recursive structure in this case, provides bootstrapped estimates of the matrices $\widetilde{A}^{1}$ and, $\widetilde{A}^{2}$.

\section{5) Calculate the bootstrapped estimates of the response vectors}

Substituting the new parameters $\widetilde{B}_{1}^{i}, \cdots, \widetilde{B}_{p}^{i}$ and $\widetilde{A}^{i}$ into equations (6) and (7) gives bootstrapped estimates of the response vectors $\theta_{k, 1}^{i}, \ldots, \theta_{k, h}^{i}$ for $k=1, . ., K$ and $i=1,2$.

Applying the above five steps for a sufficiently large number of histories gives a numerical approximation of the distribution of the original estimates of the regime vectors. In this analysis, bootstrapping is conducted 100 times. ${ }^{14}$ The distribution thus obtained underpins the confidence interval bands added to the impulse response functions.

\footnotetext{
${ }^{14}$ Further increasing the number of times bootstrapping conducted does not significantly affect the confidence intervals.
} 


\section{Model with an Explicit Interest Rate Channel}

Among the VAR models on the monetary policy transmission mechanism, the five variables model, consisting of output $y$, the price level $p$, the commodity price $c$, the call rate $i$, and the money stock $m$, has been intensively examined. This is because it allows the "price puzzle" to be avoided. The price puzzle is the term used to describe the tendency observed in impulse response analysis for the price level to increase immediately after monetary tightening, i.e. following a rise in nominal interest rates. As described in Walsh (1998), "the most commonly accepted explanation for the price puzzle is that it reflects the fact that the variables included in the VAR do not span the information available to the FED in setting the funds rate." In this regard, Sims (1992) finds that inclusion of commodity prices, which are supposed to be sensitive to changing forecasts of future inflation and therefore provide additional information for monetary policy decision making, tends to mitigate the problem of the misspecification of the central bank's information set. For this reason, the five variable VAR has generally been adopted as the standard approach [see Christiano, Eichenbaum and Evans (1999) and Teruyama (2001)]. ${ }^{15}$

In this section, we examine this five variables VAR. All data are on a monthly basis, ${ }^{16}$ and variables other than the call rate are transformed into log levels. ${ }^{17}$

\footnotetext{
${ }^{15}$ Recently, however, several pieces of new research have made findings to oppose this common view. Hanson (2000) deals with the price puzzle in some depth and concludes that the inclusion of a leading price level indicator does not necessarily solve the puzzle. Further, Barth and Ramey (2001) conclude that monetary tightening may increase firms' costs and that this could be enough to explain the increase in the price level immediately after the increase in nominal interest rates. This channel of the monetary policy transmission is called the cost channel.

${ }^{16}$ In detail, the data employed in this paper are as follows. Output: seasonally adjusted industrial production (Ministry of Economy, Trade and Industry); the price level: the seasonally adjusted Consumer Price Index excluding perishables at 2000 prices (Ministry of Public Management, Home Affairs, Posts and Telecommunications); the commodity price: Nikkei commodity price (Nikkei Shimbun); the call rate: with collateral bases (Bank of Japan); the money stock: seasonally adjusted M2+CDs, where the discontinuity due to the change in definitions is solved by using the quarterly growth rate (Bank of Japan); and the bond yield: yield on newly issued 10-year government bonds (The Japan Bond Trading Co.).

${ }^{17}$ To capture the non-negativity constraint on nominal interests in the VAR models in this paper, it is possible to use the log of the call rate as an endogenous variable. However, there
} 
Concerning the estimated results, in all MSVARs estimated in this paper, the linearity test suggests that the model is significantly non-linear and parameters switch substantially between regimes. Furthermore, each regime is highly persistent according to the transition matrix. This suggests that regime dependent impulse responses will prove to be a useful analytical tool for analysis on the Japanese monetary transmission mechanism.

As for the model specification, although not shown here, diagnostic tests confirm that errors can be considered normally and independently distributed. Hence, even if some of the endogenous variables are not stationary, this does not impose any problem on estimations.

Figure 1 shows smoothed regime probabilities, which suggest that the economy is in regime one until 1995 and then in regime two after 1999. The period between 1995 and 1999 can be considered as a transition period.

The impulse responses to a nominal interest rate shock are shown in figure 2. Thick lines show the impulse responses based on the point estimates, while the dotted lines represent point-wise confidence intervals using the 10th and 90th percentile values generated by the bootstrapping method.

In regime one, a positive shock to the call rate will lower the output, the commodity price and the money stock. In contrast to the standard theory of the monetary economics, monetary tightening here induces a higher price level

exist several problems in transforming interest rates into log levels. 1) The Euler equation tells us that the log of consumption or output is linearly related to the logs of gross interest rates, which are approximated as net interest rates. 2) Changes in the nominal interest rate below $1 \%$ become implausibly influential in the determination of output and the price level. For example, a $0.5 \%$ change in the call rate when it is $5 \%$ has the same impact on changes in output and the price level as a $0.01 \%$ change when it is $0.1 \%$. This results in a larger degree of variability in the policy instrument after 1996 than before. Hence, even with the linear VAR model, if we include periods after 1996 in the estimation period with the log of the call rate as a policy variable, the shape of the impulse responses becomes peculiar. 3) Due to the high degree of variability in the log of the call rate, it is difficult to identify distinct regime changes using the Markov switching model.

Further, there is only the smallest of risks that nominal interest rates will become stuck at the zero nominal interest rate bound in the analysis in this paper. 


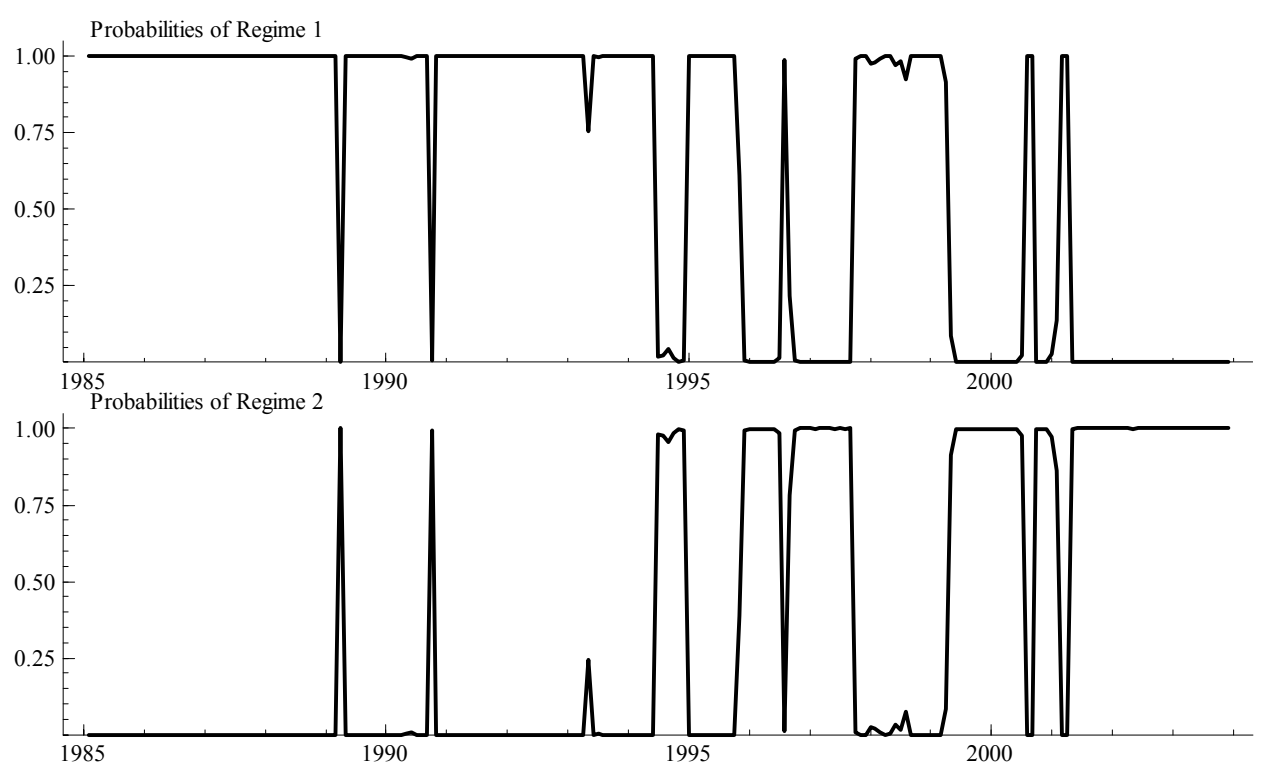

Figure 1: Regime Probabilities for MSVAR(5)
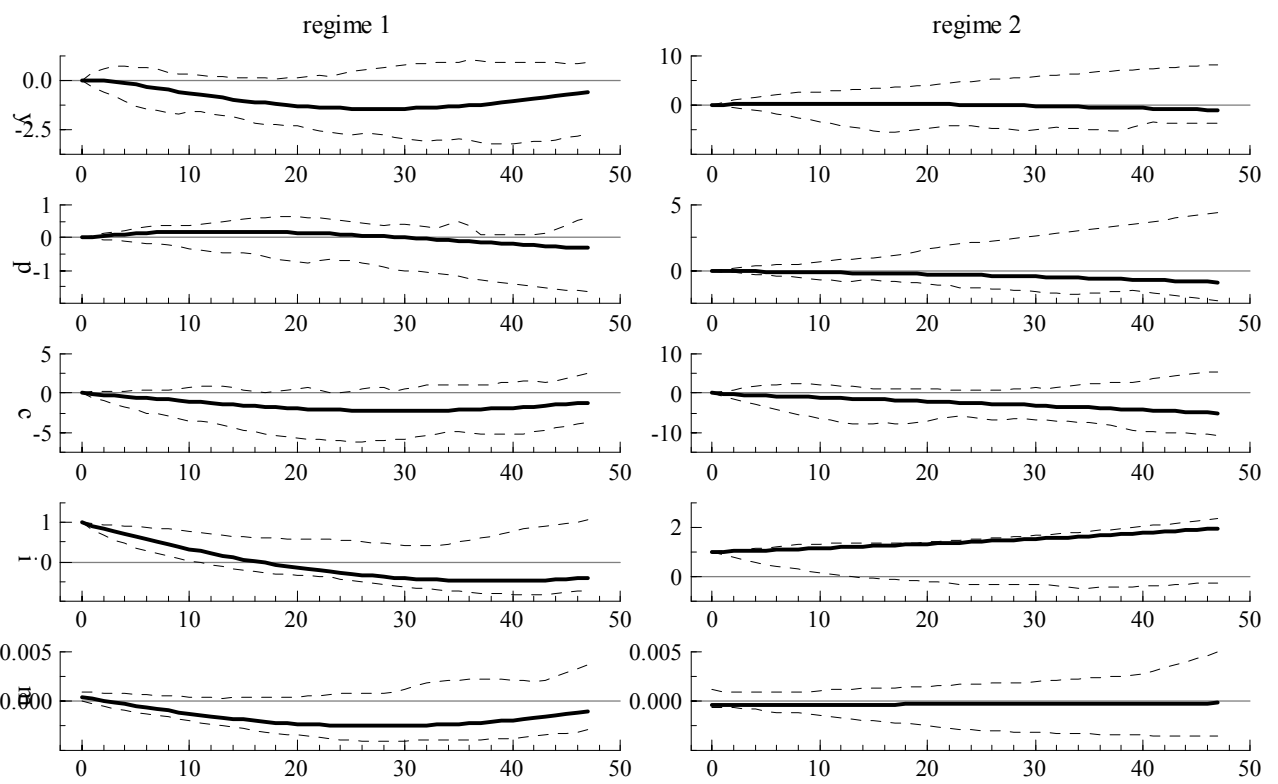

Figure 2: Impulse Responses to a Nominal Interest Rate Shock for MSVAR(5) 
initially. This is indeed the price puzzle.

On the other hand, in regime two, a positive shock to nominal interest rates causes no significant impact on other variables. As shown in figure 1, regime two covers the period when the short term nominal interest rate is constrained at the level of being almost zero. Therefore, it can be said that this result hints the declining effectiveness of monetary policy through the traditional interest rate channel.

However, it may be considered to be the obvious result of the de-facto zero nominal interest rate policy since there was almost no room left for stimulating the economy via the traditional interest rate channel. Therefore It may not be a very judicious idea to include the interest rate channel explicitly in VAR models for periods when the nominal interest rate is constrained at zero.

In March 2001, the Bank of Japan resumed a new monetary policy scheme called "quantitative easing" as an alternative device of monetary policy to the traditional short-term interest rate control. With the quantitative easing scheme, the Bank of Japan began to target the outstanding balance of the current accounts instead of the overnight call rate. In the next section, we evaluate this quantitative easing policy, namely the monetary policy with the base money as a control variable.

\section{Model with an Implicit Interest Rate Channel}

In the previous section, it was not strictly feasible to compare the effects of monetary expansion in regime one with those in regime two. This is because although the interest rate channel is no longer functioning after 1996, it is still included in the sample. In addition, the monetary policy rules employed by the Bank of Japan are likely to be very different before and after 1996. After 1996, there was very limited room for further lowering nominal interest rates. 
Responding to these caveats, we further estimate two MSVAR models. One is the three variables MSVAR comprised of the price level, the output, and the base money $b$, and the other is the four variables MSVAR with the price level, output, the base money, and bond yields $l$. All data are on monthly basis and are transformed into log levels. In both cases, the monetary policy via the base money control is conducted using contemporaneous information on output and the price level as in the five variables MSVAR examined in the previous section.

The motivation behind constructing these two models here is to gain an insight into how the non-negativity constraint on nominal interest rates influences the effects of a base money expansion which is indeed consistent with the quantitative easing policy, the current monetary policy scheme taken by the Bank of Japan. At the same time, these models have also enabled us to avoid any potential distortion of the estimation arising from the inclusion of the call rate which has been almost fixed since 1996. Therefore, these two models are, in effect, considered VAR models with an implicit interest rate channel.

Such an analysis of the monetary transmission mechanism, which excludes an explicit interest rate channel, may be subject to the criticism that it offers only a poor reflection of reality and hence is of little real use. There exist, however, a number of previous research supporting the existence of alternative channels through which money may impact upon other macroeconomic variables, even when the zero nominal bound impedes the effective functioning of the traditional interest rate channel. Koenig (1990) reports that empirically real money growth enters the consumption equation positively and significantly and hints the existence of the "direct effects of money." 18

Recently, some academic economists, such as McCallum (2000) and Orphanides and Wieland (2000), insist the existence of the "portfolio re-balancing

\footnotetext{
${ }^{18}$ Ireland (2001) constructs a model where the utility obtained from consumption and money holdings are non-separable so that money may have a direct effect on the consumption decision. In practice, however, the effect through this channel turns out to be minuscule.
} 
effect," 19 and consider the quantitative easing as one of the measures for combating deflation under zero nominal interest rates. According to this theory, as long as money is not a perfect substitute for other assets, monetary expansion affects nominal demand through both wealth and substitution effects on real assets, and through adjustments in a wide range of financial yields relevant to expenditure decisions.

Moreover, according to Okina and Shiratsuka (2003), "Even though short term interest rates decline to virtually zero, a central bank can produce further easing effects by a policy commitment. A central bank can influence market expectations by making an explicit commitment as to the duration it holds short-term interest rates at virtually zero. If it succeeds in credibly extending its commitment duration, it can reduce long-term interest rates. We call this mechanism the 'policy duration effect,' following Fujiki and Shiratsuka (2002)." The Bank of Japan intends to intensify this policy duration effect with the introduction of the quantitative easing policy. On March 19, 2001, the Monetary Policy Meeting of the Bank of Japan released the "new procedures for money market operations and monetary easing." It says that "The new procedures for money market operations continue to be in place until the consumer price index (excluding perishables, on a nationwide statistics) registers stably a zero percent or an increase year on year." The "new procedures for money market operations" is indeed the adoption of the quantitative easing policy, namely changes in the operating target for money market operations from the uncollateralized overnight call rate to the outstanding balance of the current accounts at the Bank of Japan. Furthermore, for the effective conduct of this new procedure, the Bank of Japan declared that "The Bank will increase the amount of its outright purchase of long-term government bonds from the current 400 billion

\footnotetext{
${ }^{19}$ Kimura, Kobayashi, Muranaga and Ugai (2002) provide three candidate channels through which this effect may operate: a relative asset-supply effect, a reduction in transaction costs achieved through ample supply of money, and an expectations effect.
} 
yen per month, in case it considers that increase to be necessary for providing liquidity smoothly." It is written in the minutes of the Monetary Policy Meeting of March 19, 2001 that "One member proposed that in the current environment where reducing interest rates would have only a limited effect on the economy, the Bank should consider increasing the amount of government bonds it bought outright, in order to affect the public's expectations and underline the Bank's commitment to the targeted interest rate in terms of duration." Therefore, an increase in the base money also implies strong commitment in terms of policy duration and possibly, at the same, further monetary easing in the future, the effect through which is emphasized by Auerbach and Obstfeld (2003). The four variables MSVAR is rather aimed at capturing this policy duration effect. The basic idea of the identification behind this model assumes that commitment to the quantitative easing policy reinforces the policy duration effect and therefore, lowers bond yields through the term structure of interest rates.

Although we do not specify any particular candidate for the transmission channels of monetary expansion, they are implicitly included in the models estimated below. Two MSVAR models here examined effectively offers a commentary on how the introduction of the zero rate affected the transmission channels of monetary policy.

Let us first explain about the three variables MSVAR. Figure 3 shows smoothed regime probabilities, which seem to suggest the prevalence of regime one until 1998 and of regime two after 1998.

Impulse responses to a base money shock are shown in Figure 4. In both regimes, a base money expansion results in higher levels of prices and output. However, this positive effect is smaller and less long-lived in regime two than in regime one. Furthermore, effects are not significant at all in regime two. These results indicate that although we can still recognize some slightly positive 


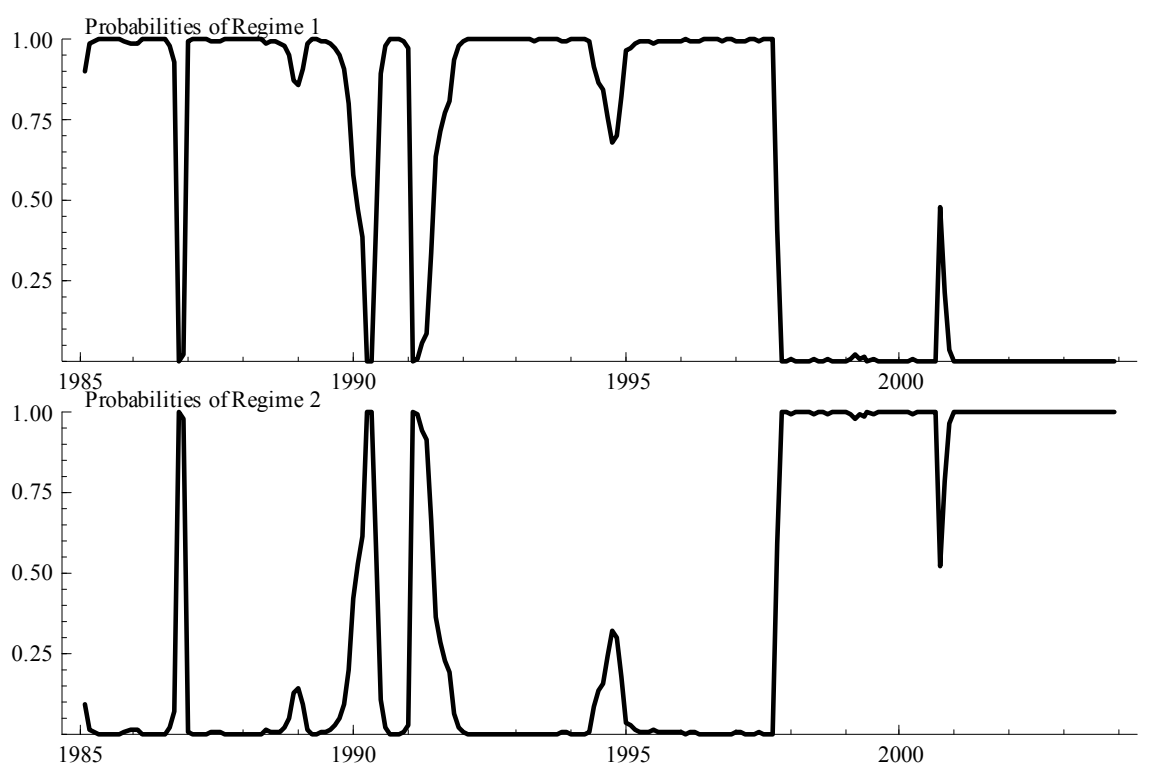

Figure 3: Regime Probabilities for MSVAR(3)

effects, the effectiveness of monetary expansion is significantly reduced after 1998, namely, when nominal interest rates are constrained at the almost zero level.

As for the four variables MSVAR, figure 5 demonstrates smoothed regime probabilities. Although there exists some short-lived switching, these figures suggest that the Japanese economy was in regime one up until 2000, around the time when the Bank of Japan resumed quantitative easing policy, and has been in regime two since then.

Figure 6 illustrates impulse responses to a base money expansion. In both regimes, a base money expansion results in higher levels of prices and output, and lower bond yields. These results indicate the possibility that there exist some small positive effects from monetary expansion through combinations of the direct effects of money, the portfolio re-balancing effects, and policy duration 

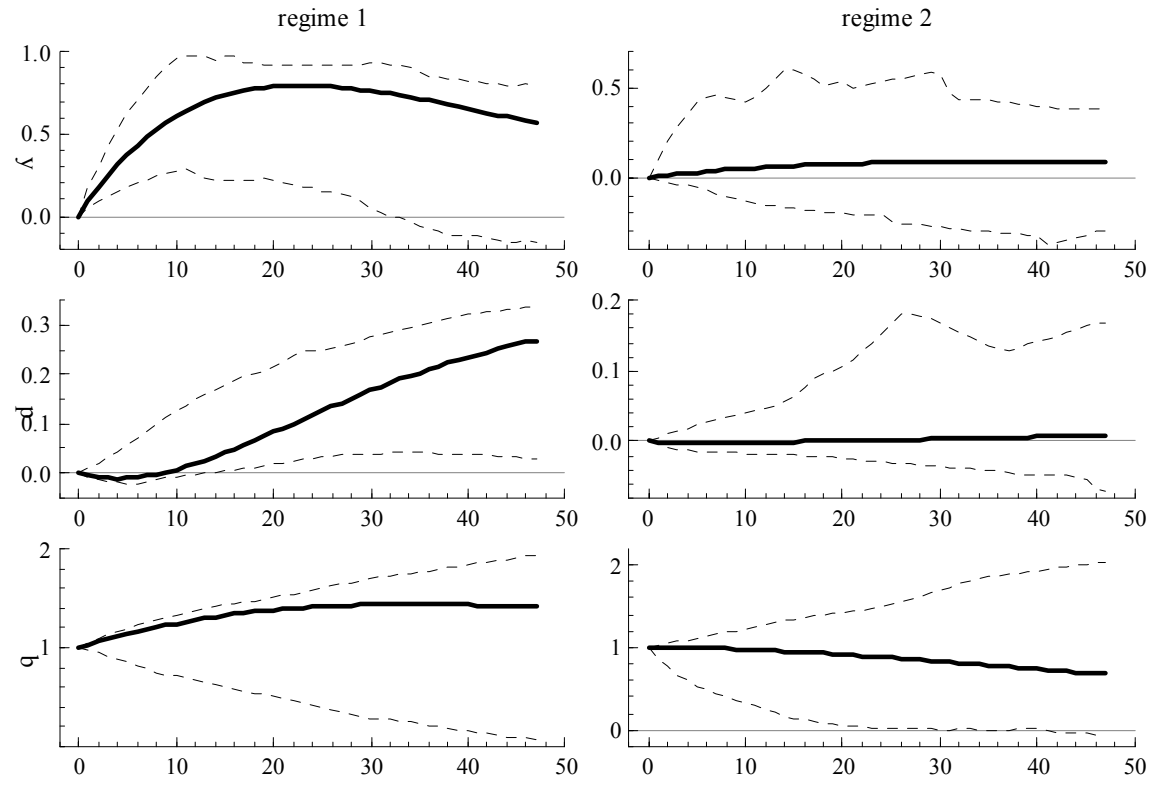

Figure 4: Impulse Responses to a Base Money Shock for MSVAR(3)
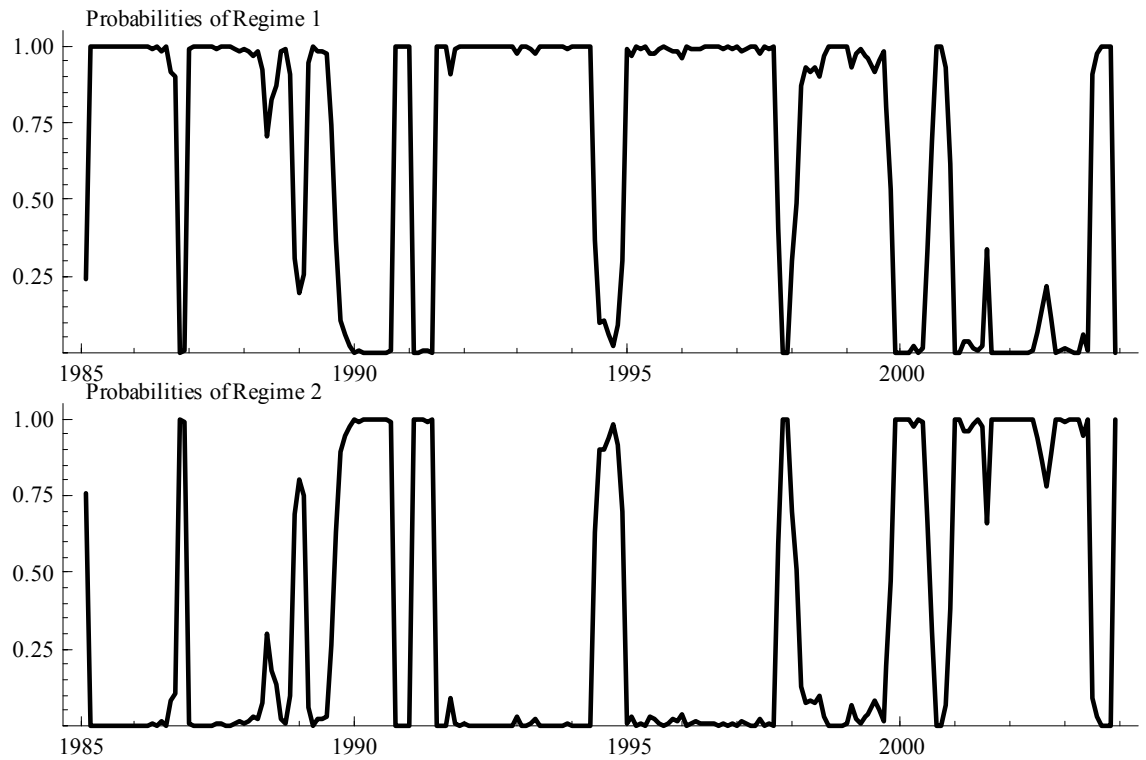

Figure 5: Regime Probabilities for MSVAR(4) 

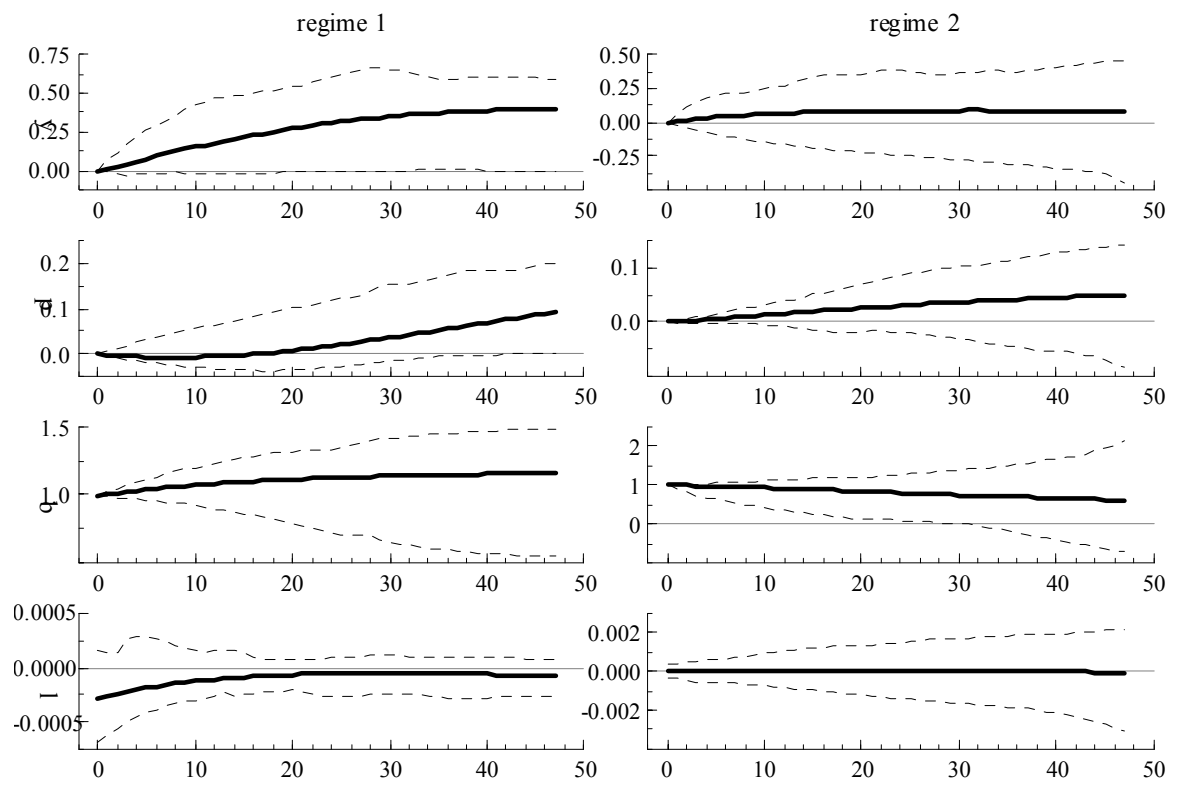

Figure 6: Impulse Responses to a Base Money Shock for MSVAR(4)

effects, even when nominal interest rates are constrained at the almost zero. However, these positive effects on the economy as a whole are insignificant in regime two. We can, therefore, conclude that the effectiveness of the current quantitative easing policy is very limited.

\section{Conclusion}

Several intriguing results are obtained from the three identified MSVAR models estimated in this paper. The findings may be summarized as follows. 1) There seems to be a structural break in the macroeconomic dynamics describing the monetary transmission mechanism around the time when the Bank of Japan resumed the de-facto zero nominal interest rate policy in the mid 1990s. 2) Even though there is no room for monetary easing by means of lowering interest rates, monetary expansion seems to have some slightly positive but statistically 
insignificant effects. 3) The impact of monetary policy on the macroeconomy using monetary expansion becomes significantly weaker after the structural break, suggesting that within the regime currently prevailing, monetary policy is not fulfilling its desired role. In short, it is now less effective than it was before the mid of 1990s at influencing output or the price level.

These findings support the similar conclusions of Miyao (2000) and Kimura, Kobayashi, Muranaga and Ugai (2002) with regard to the reduced effectiveness of monetary policy. Recent research by Boivin and Giannoni (2003), on the other hand, presents an alternative point of view: "Recent studies using vector autoregressions (VARs) find that the impact of monetary policy 'shocks' - defined as unexpected exogenous changes in the Federal funds rate - have had a much smaller impact on output and inflation since the beginning of the 1980s..... An alternative interpretation could thus be that monetary policy itself has come to systematically respond more decisively to economic conditions, thereby moderating the real effects of demand fluctuations. In this case, the change in the responses to monetary shocks would reflect an improvement in the effectiveness of monetary policy." Observing, however, that the putative structural break occurs along with the introduction of the de-facto zero nominal interest rate policy, it is scarcely plausible to assume that smaller responses to monetary shocks are due to an improvement in the efficacy of monetary policy in Japan. It may therefore be safely concluded that the effectiveness of monetary policy has indeed deteriorated in Japan during the 1990s.

The results from the three variables VAR still indicate that the effects of monetary expansion are significantly smaller after the break. They suggest that the current problem confronting the Bank of Japan, namely the deflation under zero nominal interest rates, is not tractable. Monetary expansion without the transmission channel of nominal interest rates lacks impact on macroeconomic 
variables.

The existence of this break in the macroeconomic dynamics has some very important implications for macroeconomic modelling. This is true of both VAR and DSGE models. Needless to say, VAR analysis of macroeconomic dynamics which does not take into consideration a possible structural break may lead the researcher to misjudge the current state of economy and to make the wrong policy prescription. ${ }^{20}$ Even the DSGE analysis, regardless of whether it is subject to a weak or strong economic interpretation (following the terminology of Geweke(1999)), ${ }^{21}$ a model whose parameters are determined based on the whole sample may fail to explain the current state of the economy correctly. The recent tendency for DSGE analysis to become more data-oriented, i.e. to offer a "stronger" econometric interpretation, as in Ireland (1999) and Smets and Wouters (2002), should be encouraged as it makes DSGE more realistic and hence more relevant to policy analysis. However, caution always needs to be applied when using the model to analyze current economic state because there may have been some structural breaks and the economic dynamics at that particular time may be quite different from those that prevailed in earlier periods. When conducting monetary policy, it is more important to recognize the current economic dynamics than the average economic dynamics which were prevalent in the past.

\footnotetext{
${ }^{20}$ Indeed, Kimura, Kobayashi, Muranaga and Ugai (2002) criticize Baig (2003) who argues that Japan's data support the existence of the monetary base channel even at zero interest rates on results obtained from a time invariant VAR for the whole sample.

${ }^{21}$ A "weak econometric interpretation" is one where the parameters of the DSGE model are calibrated in such a way that selected theoretical moments given by the model match those observed in the data as closely as possible. This is the interpretation pioneered by Kydland and Prescott (1982). On the other hand, the strong econometric interpretation attempts to provide a full characterization of the observed data series. Details on the these two interpretations are found in Geweke (1999) or Smets and Wouters (2002).
} 


\section{References}

[1] Auerbach, Alan, and Maurice Obstfeld. (2003). "The Case for Open-Market Purchases in a Liquidity Trap." Mimeo, University of California, Berkeley.

[2] Baig, Taimur. (2003). Monetary Policy in a Deflationary Environment. In Ending the Lost Decade: Policies to Revive Japan's Stagnant Economy, edited by Tim Callen and Jonathan Ostry, pp. 206-223. Washington DC: International Monetary Fund.

[3] Barth, Marvin, and Valerie Ramey. (2001). "The Cost Channel of Monetary Transmission." In NBER Macroeconomics Annual, edited by Ben Bernanke and Kenneth Rogoff, pp. 199-240. Cambridge, MA: MIT Press.

[4] Bayoumi, Tamin, and Charles Collyns. (1990). Post-Bubble Blues. Washington DC: International Monetary Fund.

[5] Bernanke, Ben. (1986). "Alternative Explanation of the Money-Income Correlation." Carnegie-Rochester Conference Series on Public Policy 25, 49-99.

[6] Boivin, Jean, and Marc Giannoni. (2003). "Has Monetary Policy Become More Effective." NBER Working Paper No. 9459.

[7] Cecchetti, Stephen, and Georgios Karras. (1994). "Sources of Output Fluctuations during the Interwar Period: Further Evidence on the Causes of the Great Depression." Review of Economics and Statistics 76, 80-102.

[8] Choi, In. (2002). "Inconsistency of Bootstrap for Nonstationary, Vector Autoregressive Process." Mimeo, Hong Kong University of Science and Technology. 
[9] Christiano, Lawrence, (1986). "Money and the US economy in the 1980s: A Break from the Past?" Federal Reserve Bank of Minneapolis Quarterly Review, 2-13.

[10] Christiano, Lawrence, Martin Eichenbaum, and Charles Evans. (1999). "Monetary Policy Shocks: What Have We Learned and to What End?" In Handbook of Macroeconomics 3A, edited by John Taylor and Michael Woodford, pp. 65-148. Amsterdam: Elsevier Science.

[11] Ehrmann, Michael, Martin Ellison, and Natacha Valla. (2003). "RegimeDependent Impulse Response Functions in a Markov-Switching Vector Autoregression Model." Economics Letters 78, 295-299.

[12] Fujiki, Hiroshi, and Shigenori Shiratsuka. (2002). "Policy Duration Effect under the Zero Interest Rate Policy in 1999-2000: Evidence from Japan's Money Market Data." Monetary and Economic Studies 20, 1-31.

[13] Garcia, Rene. (1998). "Asymptotic Null Distribution of the Likelihood Ratio Test in Markov Switching Models." International Economic Review 39, 763-788.

[14] Geweke, John. (1999). "Computational Experiments and Reality." Mimeo, University of Minnesota.

[15] Hamilton, James. (1989). "A New Approach to the Economic Analysis of Nonstationary Time Series and the Business Cycle." Econometrica 57, 357384 .

[16] Hamilton, J., 1994 Time Series Analysis. Princeton University Press, Princeton.

[17] Hanson, Michael. (2000). "The 'Price Puzzle' Reconsidered." Mimeo, Wesleyan University. 
[18] Hayashi, Fumio, and Edward Prescott. (2002). "Japan's lost decade." Review of Economic Dynamics 5, 206-235

[19] Ireland, Peter. (1999). "A Method for taking models to the data." Mimeo, Boston College.

[20] Ireland, Peter. (2001). "The Real Balance Effect." Mimeo, Boston College.

[21] Kim, Chang-Jin, and Charles Nelson. (1999). State-Space Models with Regime Switching. Cambridge MA: MIT Press.

[22] Kimura, Takeshi, Hiroshi Kobayashi, Jun Muranaga, and Hiroshi Ugai. (2002). "The Effect of the Increase in Monetary Base on Japan's Economy at Zero Interest Rates: An Empirical Analysis." In Monetary Policy in a Changing Environment, pp. 276-312. Basle: Bank for International Settlements.

[23] Koenig, Evan. (1990). "Real Balances and the Timing of Consumption: An Empirical Investigation." Quarterly Journal of Economics 105, 399-425.

[24] Krolzig, Hans-Martin, (1997). Markov Switching Vector Autoregressions. Modeling, Statistical Inference and Application to Business Cycle Analysis. Berlin: Springer.

[25] Krolzig, Hans-Martin, (1998). "Economic Modelling of Markov-Switching Vector Autoregressions using MSVAR for Ox." Mimeo, Nuffield College.

[26] Krolzig, Hans-Martin, and Juan Toro. (1999). "A New Approach to the Analysis of Shocks and the Cycle in a Model of Output and Employment." EUI Working Paper ECO 99/30.

[27] Kydland, Finn, and Edward Prescott. (1982). "Time to Build and Aggregate Fluctuations." Econometrica 50, 1345-1370. 
[28] Leeper, Eric, Christopher Sims and Tao Zha. (1996). "What Does Monetary Policy Do?" Brookings Papers on Economic Activity 2, 1-63.

[29] McCallum, Bennet. (2000). "Theoretical Analysis Regarding a Zero Lower Bound on Nominal Interest Rates." Journal of Money, Credit and Banking $32,870-904$.

[30] Miyao, Ryuzo. (1996). "Does a Cointegrating M2 Demand Relation Really Exist in Japan?" Journal of the Japanese and International Economies 10, 169-180.

[31] Miyao, Ryuzo. (2000). "The Role of Monetary Policy in Japan: A Break in the 1990s?" Journal of the Japanese and International Economies 14, 366-388.

[32] Miyao, Ryuzo. (2002). "The Effects of Monetary Policy in Japan." Journal of Money, Credit and Banking 34, 176-392.

[33] Neftci, Salih. (1984). "Are Economic Time Series Asymmetric over the Business Cycle?" Journal of Political Economy 92, 307-328.

[34] Okina, Kunio, and Shigenori Shiratsuka. (2003). "Policy Commitment and Expectation Formations: Japan's Experience under Zero Interest Rates." IMES Discussion Paper Series 2003E-5. Institute for Monetary and Economic Studies, Bank of Japan.

[35] Orphanides, Athanasios, and Volker Wieland. (2000). "Efficient Monetary Policy Design near Price Stability." Journal of the Japanese and International Economies 14, 327-365.

[36] Ramaswamy, Ramana, and Christel Rendu. (2000). "Japan's Stagnant Nineties: A Vector Autoregression Retrospective." IMF Staff Papers 47, 259-277. 
[37] Sims, Christopher. (1980). "Macroeconomics and Reality." Econometrica $48,1-48$.

[38] Sims, Christopher. (1986). "Are Forecasting Models Usable for Policy Analysis?" Federal Reserve Bank of Minneapolis Quarterly Review, 3-16.

[39] Sims, Chrisopher. (1992). "Interpreting the Macroeconomic Time Series: the Effects of Monetary Policy." European Economic Review 36, pp. 9751000.

[40] Sims, Christopher, James Stock and Mark Watson. (1990). "Inference in Linear Time Series Models with Some Unit Roots." Econometrica 58, 113144.

[41] Smets, Frank, and Rafael Wouters. (2002). "An Estimated Stochastic Dynamic General Equilibrium Model of the Euro Area." ECB Working Paper Series 171.

[42] Teruyama, Hiroshi. (2001). "VAR niyoru kinyuseisaku no bunseki: tenbou (Analysis of Monetary Policy using VAR: A Perspective.)" Financial Review September-2001, 74-140.

[43] Walsh, Carl. (1998). Monetary Theory and Policy. Cambridge MA: MIT Press. 